\title{
Nickel Monoxide
}

National Cancer Institute

\section{Source}

National Cancer Institute. Nickel Monoxide. NCI Thesaurus. Code C45864.

A green to black colored, inorg anic compound that turns yellow and produces toxic gases upon heating. Nickel monoxide is used in the electronics, ceramics, steel and alloy industries. Exposure to this substance can cause severe dermatitis, skin and asthma-like allergies and damages the lungs, kidneys, gastrointestinal tract and neurological system. Nickel monoxide is a known carcinogen and is associated with an increased risk of developing lung and nasal cancers. ( $\mathrm{NCl} 05)$ 